\title{
ВMJ Global Health Digital communities of practice: one step towards decolonising global health partnerships
}

Carmen Sant Fruchtman (D) , 1,2 Muhammad Bilal Khalid (D) , ${ }^{3}$

Tshiamo Keakabetse (D) , ${ }^{4}$ Antonio Bonito, ${ }^{5}$ Dell D Saulnier (D) , ${ }^{6}$ Lucia Mungapeyi Mupara (D) , ${ }^{4}$ Shahid lqbal (D) , ${ }^{3}$ Afonso de Almeida, ${ }^{7}$ Hendriketa da Silva, ${ }^{7}$ Diamantino de Jesus, ${ }^{7}$ Helen Prytherch, ${ }^{2,8}$ Ellen Mokalake, ${ }^{4}$ Daniel Cobos Muñoz (D) , ${ }^{1,2}$ Shamsa Zafar (D) ${ }^{9}$

\begin{abstract}
This commentary is dedicated to the memory of Diamantino de Jesus from the Universidade Nacional de Timor Loro-Sae who was an active member of the community of practice $(\mathrm{CoP})$ until his untimely death on 8 September 2021.
\end{abstract}

To cite: Sant Fruchtman C, Bilal Khalid M, Keakabetse T, et al. Digital communities of practice: one step towards decolonising global health partnerships. BMJ Global Health 2022;7:e008174. doi:10.1136/ bmjgh-2021-008174

Handling editor Seye Abimbola

DCM and SZ contributed equally.

Received 2 December 2021 Accepted 29 December 2021

Check for updates

(c) Author(s) (or their employer(s)) 2022. Re-use permitted under CC BY-NC. No commercial re-use. See rights and permissions. Published by BMJ.

For numbered affiliations see end of article.

Correspondence to

Ms Carmen Sant Fruchtman;

c.santfruchtman@swisstph.ch
The COVID-19 pandemic radically changed peoples' lives. In our work, restrictions on social interaction and travel forced us to rethink the way our global health organisations operate. Building partnerships and sustaining collaborations have been particularly challenging as regular in-person meetings have been replaced by online setups. However, we see an opportunity for global health partnerships and practice during this shift. There have been many recent calls to decolonise global health and radically revise the current global health structures, including to critically reflect and reform partnerships. ${ }^{1}{ }^{2}$ Historically, multicountry global health partnerships have been characterised by the limited exchange of ideas or space for leadership among the low-income and middle-income country colleagues, despite their expertise and contextual knowledge. ${ }^{3}$ Institutions from the Global North have tended to act as leaders with experts from countries in the Global South, where these projects are implemented, too often relegated to a secondary role of 'local partners. ${ }^{4}$

These structural disparities have led to a fundamental imbalance in knowledge production and use. ${ }^{5}$ In this commentary, we argue that, when used consciously, digital ecosystems can enable the development of more just and equal partnerships where learning takes place in all different directions. We present an example of the

\section{Summary box}

- Historically, global health partnerships have been led by scholars in high-income countries with colleagues from low-and middle-income countries acting as 'local' partners.

- The COVID-19 pandemic and the response to it, including travel bans, as well as ongoing discussion and movements to decolonise Global Health have finally accelerated changes in our collaboration patterns.

- We describe lessons from the shift to a digital community of practice, which combined with a strong intention to treat all partners as equal entities, resulted in the emergence of a more horizontal and inclusive partnership across and between research institutions in the Global North and South.

- The flexibility of the funder to adapt to the emerging needs and approaches, as well as an equal funding scheme across institutions, facilitated the initiation and success of the community of practice.

- The online community of practice enabled multidirectional peer-to-peer learning and coproduction of knowledge.

transition of an in-person capacity building initiative for systems thinking into an online community of practice $(\mathrm{CoP})$. We share some of the lessons learnt from the perspectives of the researchers in the CoP from 18 months of practice.

\section{HOW TRANSITIONING TO AN ONLINE COP ENABLED A MORE EQUAL PARTNERSHIP}

In November 2019, the Systems Thinking for District Health Systems Initiative (box 1) was launched. Before the pandemic, the Swiss Tropical and Public Health Institute (Swiss TPH) was to have a central role across countries. The partner research institutions were to work with Swiss TPH to 
Box 1 The systems thinking for district health systems initiative

The Systems Thinking for District Health Systems initiative (ST-DHS) was designed to support district managers to adapt, modify and use systems thinking tools at the district level. The initiative was designed to be driven by the needs and interests of district health management teams in Botswana, Pakistan and Timor Leste, facilitated by a research institution in each country. Funded by the Alliance for Health Policy and Systems Research, the initiative is a collaboration between four countries. Research institutions were selected by the Alliance for Health Policy and Systems Research to implement the initiative in the three partner countries: the Institute for Development Management in Botswana, Child Advocacy International in Pakistan and the WHO office in Timor-Leste. The Swiss Tropical and Public Health Institute was appointed as the Technical Support Centre.

carry out the implementation of systems thinking tools within each district. The exchange across countries was limited to the kick-off and dissemination activities.

In March 2020, it became clear that it would be impossible to implement the project as originally planned. The partners, including the funder, were forced to stop and reflect on how the initiative should be operationalised moving forward. A consultation process with the consortium of partners led to the creation of the digital District Systems Thinking CoP. CoPs have been described as a group of people engaging in a process of collective learning on a shared domain of interest during regular interactions. ${ }^{6}$ In our case, this was a CoP to learn and engage around the use of Systems Thinking for district health systems.

The CoP was launched in June 2020. During the initial months, the Technical Support Centre (TSC) coordinated weekly technical sessions that were hosted by Swiss TPH or by colleagues from each institution involved in the initiative. As the knowledge, experience and confidence in systems thinking grew across the different partners, Swiss TPH's role became that of a facilitator rather than the technical expert. The CoP created an environment in which learning and discussion across all four institutions happened at a peer-to-peer level, where the experiences from one district informed the activities in the other districts and vice versa. This theme became very relevant during the anonymous reflective practice sessions (see figure 1 ).

\section{WHAT LESSONS WERE LEARNT? \\ Respond to the CoPs wishes and needs}

Early on, it was clear that the CoP had to answer and adapt to the emerging needs and interests of its participants. The CoP should not be a series of meetings but an ongoing process that accompanied partners throughout a project, giving all participants a space to return to and discuss relevant issues as needed. Maintaining the engagement of all partners beyond the meetings was sometimes a challenge when there were competing priorities.

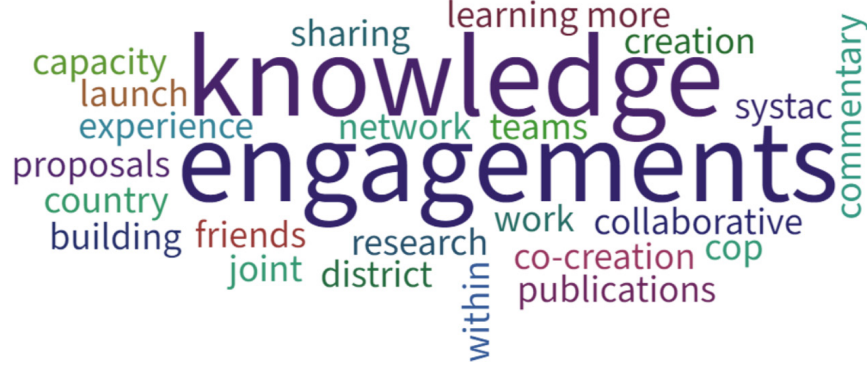

Figure 1 What have been your biggest achievements within ST-DHS? anonymous feedback provided by researchers of the COP during an end of the year reflective session (13 December 2021). CoP, community of practice; ST-DHS, Systems Thinking for District Health Systems.

It was, therefore, even more, important to have the CoP respond to the needs of all its participants for them to consider it useful and continue to invest in it. Participants were more inclined to join sessions that contributed to their areas of interest and when they were expected to be active with specific roles in the discussions. Such a degree of responsiveness required a considerable amount of time-intensive coordination. The coordination was led by Swiss TPH, which raises questions about the sustainability of such CoPs at the end of a funded project like this initiative.

\section{Embrace diversity in participants and activities}

CoPs need to provide space to acknowledge different voices and to describe and discuss local, regional and national differences and similarities. Structured reflective practice sessions were used to collect and discuss feedback about the ongoing work and CoP dynamics across the different layers of involvement-between countries, and across researchers and practitioners. These sessions included discussions, as well as anonymous feedback rounds. As a digital community, it was clear that sessions needed to be adjusted to ensure everyone could follow the pace. Simple tips included using live transcripts when there were groups with different language skills and sharing meeting recordings after sessions to let participants catch up as needed.

The initiative also embraced diversity in its activities, with each district focusing on different problems. Each country research institution led a problem identification process with the district health managers. The selected 'challenges' aligned with district objectives to avoid perceived additional workload on the already burdened health systems. For example, Institute for Development Management in Botswana facilitated the identification of a health system challenge by using a combination of systems thinking tools with the district health team. The TSC provided the initial basic orientation of systems thinking tools and it was then each research institution who decided with district managers which ones to apply. The knowledge emerging from these practical experiences has been documented as How-To Guides 
developed for each country and is being compiled in different country publications.

\section{Creation of non-hierarchical collaborations by funding agencies}

The role of the funder was crucial in the development of such a horizontal and inclusive partnership. All research institutions in this initiative were direct grantees of the overall funder. This was essential to create an environment in which all institutions had the same duties and responsibilities. The fact that no research institution was reporting to each other generated an equal playing field. We, therefore, can only recommend the creation of more such setups in which all partners can be equal towards the funder, avoiding subcontracting, especially between partners in high and those in low-income and middle-income countries.

Furthermore, the flexibility and engagement of the funder when the pandemic struck, facilitated the creation of the digital CoP, which had not been planned early on. It was key for the partnership to be run and managed following the Systems Thinking principles of adaptability and flexibility.

\section{Distribute ownership of the outputs}

The CoP grew to be a platform that enabled the co-production of knowledge. ${ }^{7}$ The research project case studies and findings will be, we hope, one of the major outputs of the initiative. Working across countries and stakeholders like decision-makers has not always been easy. However, when ownership and leadership of the projects and outputs were equally shared across individuals, including decision-makers, it supported the buy-in of most of the collaborators involved. Early publication plans were developed to agree on authorship criteria and ensure all partners had leadership opportunities. This increased motivation and led to the generation of new project and research ideas. One example is a comparative study of the district health information system of Gaborone and Rajanpur using causal loop diagrams. The idea for the study was identified by researchers from both countries during a CoP session when the teams realised how many similarities existed between the two districts. Further collaborations across institutions have emerged and expanded beyond the current initiative. These have included, among others, the development of new proposals led by different members of the CoP and training material. A systems thinking course for health managers was conducted in Iran and members of the CoP led a 1-day workshop. Furthermore, all CoP members have also taken an active role in the emerging global community of systems thinkers, the Systems Thinking Accelerator (SYSTAC).

\section{Work from the local to the global and back to the local}

In addition to the multicountry digital CoP, each country aimed to develop their local CoP. In a multicountry collaboration, having these in-country CoPs where district managers and national stakeholders work with the research institutions, was seen as crucial to allow local, bottom-up ideas to arise and help to establish the systems thinking practices in the districts. So far most engagements in the country have been bilateral of the research institution with the different stakeholders. A multistakeholder CoP remains in the making, given the challenges raised by the COVID-19 pandemic and the lack of connectivity in certain areas. Furthermore, trust is crucial to establishing a relevant, sustainable CoP, but building this trust requires time and effort. We expect that the in-country CoPs should connect to the multicountry CoP so that learning will be ensured both across countries and within the individual countries.

\section{CONCLUSION: TOWARDS MORE JUST GLOBAL HEALTH PARTNERSHIPS}

From our experience with the online CoP, we believe that when used consciously, online CoPs can facilitate the development of more equitable, horizontal partnerships. Establishing such a CoP puts the coproduction of knowledge at the heart of the partnership. Still, some challenges need to be addressed, such as flexibility in funding and outputs, and that those digital environments cannot fully replace human interaction. The future may not be lived fully online but the gains for more just global collaborations are already becoming clear. We foresee that the partnerships and friendships developed within such an environment can live beyond the end of a funded project.

\section{Author affiliations}

${ }^{1}$ Epidemiology and Public Health, Swiss Tropical and Public Health Institute, Basel, Switzerland

2University of Basel, Basel, Switzerland

${ }^{3}$ Child Advocacy International, Islamabad, Pakistan

${ }^{4}$ Public Health, Institute for Development Management, Gaborone, Botswana

${ }^{5}$ World Health Organization Country Office for Timor-Leste, Dili, Timor-Leste

${ }^{6}$ Global Public Health, Karolinska Institutet, Stockholm, Sweden

${ }^{7}$ Universidade Nacional de Timor Loro-Sae, Dili, Timor-Leste

${ }^{8}$ Swiss Centre for International Health, Swiss Tropical and Public Health Institute, Basel, Switzerland

${ }^{9}$ Fazaia Medical College, Islamabad, Pakistan

Twitter Carmen Sant Fruchtman @santfro, Tshiamo Keakabetse @twreckadonis, Dell D Saulnier @SaulnierDell, Helen Prytherch @Helen_Pytherch, Daniel Cobos Muñoz@Daniel_Cobos_PH and Shamsa Zafar @ShamsaRizwan

Contributors All authors are members of the Systems Thinking for Districts Community of Practice. The lessons learnt emerged from this experience. All authors participated in the conceptualisation of the commentary. CSF and DDS wrote the first draft. All authors reviewed and contributed to the final version.

Funding This work received financial support from the Alliance for Health Policy and Systems Research. The Alliance is able to conduct its work thanks to the commitment and support from a variety of funders. These include our long-term core contributors from national governments and international institutions, as well as designated funding for specific projects within our current priorities. For the full list of Alliance donors, please visit: https://www.who.int/alliance-hpsr/partners/en/.

Competing interests None declared.

Patient consent for publication Not applicable.

Ethics approval The different studies within the ST-DHS initiative were approved by the ethical review board in the four countries in which the research institutions are based.

Provenance and peer review Not commissioned; externally peer reviewed.

Data availability statement There is no additional data available from this work. 
Open access This is an open access article distributed in accordance with the Creative Commons Attribution Non Commercial (CC BY-NC 4.0) license, which permits others to distribute, remix, adapt, build upon this work non-commercially, and license their derivative works on different terms, provided the original work is properly cited, appropriate credit is given, any changes made indicated, and the use is non-commercial. See: http://creativecommons.org/licenses/by-nc/4.0/.

\section{ORCID iDs}

Carmen Sant Fruchtman http://orcid.org/0000-0002-5276-3515

Muhammad Bilal Khalid http://orcid.org/0000-0003-3986-7093

Tshiamo Keakabetse http://orcid.org/0000-0003-0725-0961

Dell D Saulnier http://orcid.org/0000-0001-7761-0737

Lucia Mungapeyi Mupara http://orcid.org/0000-0003-3497-624X

Shahid lqbal http://orcid.org/0000-0002-9211-1212

Daniel Cobos Muñoz http://orcid.org/0000-0002-5920-1304

Shamsa Zafar http://orcid.org/0000-0003-4397-5505

\section{REFERENCES}

1 Abimbola S, Asthana S, Montenegro C, et al. Addressing power asymmetries in global health: imperatives in the wake of the COVID-19 pandemic. PLoS Med 2021;18:e1003604.

2 Büyüm AM, Kenney C, Koris A, et al. Decolonising global health: if not now, when? BMJ Glob Health 2020;5:e003394.

3 Boum li Y, Burns BF, Siedner M, et al. Advancing equitable global health research partnerships in Africa. BMJ Glob Health 2018;3:e000868.

4 Sheikh K, Schneider H, Agyepong IA, et al. Boundary-spanning: reflections on the practices and principles of global health. BMJ Glob Health 2016;1:e000058.

5 Affun-Adegbulu C, Adegbulu O. Decolonising global (public) health: from Western universalism to global pluriversalities. BMJ Glob Health 2020;5:e002947.

6 Wenger E. Communities of practice: a brief introduction, 2011

7 Redman S, Greenhalgh T, Adedokun L, et al. Co-production of knowledge: the future. BMJ 2021;372: :n434. 